\title{
INFLUÊNCIA DO CONGELAMENTO SOBRE AS CARACTERÍSTICAS FÍSICO-QUÍMICAS E O POTENCIAL ANTIOXIDANTE DE NÉCTAR DE AMORA-PRETA*
}

\author{
PAULAFERREIRA DE ARAÚJO** \\ ROSANE DA SILVA RODRIGUES $* * *$ \\ ADRIANA RODRIGUES MACHADO**** \\ VALÉRIA DA SILVA SANTOS**** \\ JORGE ADOLFO SILVA
}

\begin{abstract}
A presença de compostos bioativos na amora-preta confere propriedades funcionais que estimulam a elaboração de produtos derivados. Entretanto, fatores como o processamento e o armazenamento são essenciais para a estabilidade desses produtos e para a manutenção da funcionalidade. Assim, o objetivo deste trabalho foi avaliar a influência do congelamento sobre as características físicoquímicas e o potencial antioxidante de néctar de amora-preta durante 90 dias de armazenamento. O produto foi avaliado a cada 15 dias quanto aos teores totais de compostos fenólicos, antocianinas, ácido ascórbico, atividade antioxidante, sólidos solúveis totais, $\mathrm{pH}$, acidez total e viscosidade aparente. Ao final do estudo verificou-se que o congelamento, como método de conservação, mantém a estabilidade físico-química e o potencial antioxidante do néctar de amora-preta.
\end{abstract}

* Parte da dissertação do primeiro autor.

* Bacharel em Química de Alimentos, Programa de Pós-Graduação em Ciência e Tecnologia Agroindustrial, Universidade Federal de Pelotas (UFPel), Pelotas, RS (e-mail: paulaufpel@pop.com.br).

*** Doutora em Tecnologia de Alimentos, Departamento de Ciência dos Alimentos, UFPel, Pelotas, RS (email: rosane.rodrigues@ufpel.tche.br).

*** Graduandos em Química de Alimentos, UFPel, Pelotas, RS (e-mail: adririso@hotmail.com; santosilvaleria@hotmail.com).

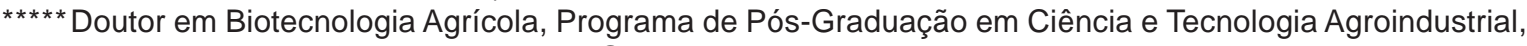
UFPel, Pelotas, RS (e-mail: ctajorge@ufpel.tche.br). 


\section{INTRODUÇÃO}

A amora-preta (Rubus spp.) apresenta elevado valor nutritivo, sendo excelente fonte de compostos fenólicos (principalmente antocianinas), destacando-se carboidratos, minerais (cálcio e potássio) e vitamina C (ANTUNES, 2002; BARBOZA, 1999; TÜREMIS et al., 2003). O cultivo expressivo da fruta ocorre em diversas regiões brasileiras como o Rio Grande do Sul, São Paulo e sul de Minas Gerais (ANTUNES et al., 2000).

Devido à sua composição química, a amora pode apresentar propriedades funcionais fisiológicas como atividade antioxidante e anticancerígena (HASSIMOTO, GENOVESE e LAJOLO, 2004), características que estimulam o seu consumo in natura ou na forma de geleias, sucos e iogurtes (GRANADA, VENDRUSCOLO e TREPTOW, 2001). Segundo HASSIMOTO et al. (2004), os frutos da amoreira-preta, cultivar Tupy, podem apresentar teores de antocianinas de $116,76 \mathrm{mg}^{1} 100 \mathrm{~g}^{-1}$, compostos fenólicos totais de $373,33 \mathrm{mg} \cdot 100 \mathrm{~g}^{-1} \mathrm{e}$ atividade antioxidante de $71,32 \%$ de inibição do descoloramento do â caroteno.

Dentre os compostos fenólicos com propriedades antioxidantes presentes na amora-preta destacam-se os flavonoides antociânicos, sendo a cianidina-3-glicosídio e cianidina-3-rutinosídio as mais representativas. Também estão presentes outros flavonoides como a quercetina, kaempferol e ácidos hidroxicinâmicos e hidroxibenzóicos (MÄÄTÄ-RIIHINENN, KAMAL-ELDIN e TÖRRÖNEN, 2004).

Os compostos fenólicos são metabólitos secundários naturalmente presentes em frutas e hortaliças e sua importância geralmente está relacionada à promoção da saúde e possível prevenção de algumas doenças, que vêm sendo estudadas em diversas pesquisas científicas (GIBNEY, MACDONALD e ROCHE, 2006).

Os radicais livres, presentes no organismo humano, causam danos oxidativos em diferentes moléculas (lipídios, proteínas e ácidos nucleicos), estando envolvidos na fase de iniciação de diversas doenças degenerativas. Os componentes celulares não são protegidos totalmente por antioxidantes endógenos, tornando os antioxidantes obtidos pela dieta indispensáveis para a defesa do organismo e manutenção da saúde (CERQUEIRA, MEDEIROS e AUGUSTO, 2007).

A funcionalidade dos compostos fenólicos baseia-se principalmente em sua ação sequestradora de radicais livres, tornando possível diminuir a incidência de patologias como aterosclerose, cataratas, câncer e inflamações crônicas (GARCIA-ALONSO et al. 2004). A capacidade antioxidante desses compostos vem sendo relacionada à presença de grupos hidroxilas em sua estrutura química e à alta reatividade dos mesmos, fatores considerados críticos para a neutralização de radicais livres (ELISIA et al., 2007). Esses compostos são extremamente instáveis podendo sofrer degradação durante as diversas etapas do processamento, armazenamento e estocagem de alimentos. As antocianinas normalmente são mais estáveis sob condições ácidas, porém podem se degradar por qualquer mecanismo que leve à formação de compostos escuros e/ou insolúveis (JACKMAN e SMITH, 1992). Essa degradação pode ocorrer durante o processamento e/ou armazenamento do alimento, sendo que os fatores de maior influência são $\mathrm{pH}$, temperatura, presença de oxigênio e enzimas, além da interação com outros componentes do alimento como ácido ascórbico, íons metálicos, açúcares e copigmentos (BOBBIO e BOBBIO, 1992). Com relação à vitamina $\mathrm{C}$, a sua concentração e estabilidade podem variar, em geral, conforme o tempo e temperatura de processamento do produto, $\mathrm{pH}$, presença de oxigênio e enzimas (MAEDA et al., 2007).

O objetivo deste trabalho foi avaliar a influência do congelamento sobre as características físico-químicas e o potencial antioxidante de néctar de amora-preta durante seu armazenamento.

\section{MATERIAL E MÉTODOS}

Foram utilizadas amoras-pretas da safra 2007/2008, Cv. Tupy, cultivadas na região sul do estado do Rio Grande do Sul, sacarose (açúcar cristal) e água mineral. 
As frutas foram colhidas no ponto de maturação considerado ideal, visualizado mediante coloração escura e uniforme da casca e do tamanho dos frutos (em torno de $6 \mathrm{~g}$ ). As amoras-pretas foram lavadas em água corrente clorada, sanitizadas em solução de cloro ativo a $100 \mathrm{mg} \cdot \mathrm{L}^{-1}$ por 10 minutos (CHITARRA, 2000) e despolpadas em despolpadeira mecânica com peneira de 0,8 mm (LEITÃO, 2007).

Preparou-se o néctar pela mistura da polpa de amora-preta com água mineral na proporção de 1:1(p/p) e adição de sacarose até $13^{\circ}$ Brix, conforme LEITÃO (2007). Acondicionou-se o néctar em garrafas de polipropileno randômico (PP) com capacidade para $250 \mathrm{~mL}$, que foram armazenadas sob congelamento $\left(-18 \pm 2^{\circ} \mathrm{C}\right)$ em freezer vertical durante 90 dias.

Avaliou-se o potencial antioxidante do produto a cada 15 dias, durante 90 dias de armazenamento, sendo determinados, em triplicata, os teores totais de compostos fenólicos e antocianinas, ácido ascórbico e a atividade antioxidante.

Determinou-se o conteúdo total de compostos fenólicos mediante adaptação do método de Folin-Ciocalteau de acordo com KIRALP e TOPPARE (2006). A quantificação dos compostos baseouse na estruturação de curva padrão com $R^{2}=0,9986$, sendo os resultados expressos em miligramas de ácido gálico equivalente por 100 gramas de néctar.

As antocianinas totais foram expressas conforme FULEKI e FRANCIS (1968) com algumas adaptações. Utilizou-se 1 grama de amostra do produto em $25 \mathrm{~mL}$ de solução extratora (etanol pH 1,0 ), seguido de incubação por uma hora em temperatura ambiente. Os resultados foram expressos em miligramas de cianidina 3-glicosídeo por 100 gramas de néctar.

Os teores de vitamina $C$ foram determinados pelo método de redução dos íons cúpricos, de acordo com CONTRERAS, STRONG III e GUERNELLI (1984), utilizando-se curva padrão com equação da reta $y=0,0636 x-0,0128$ e $R^{2}=0,9809$. Os resultados foram expressos em miligramas de ácido ascórbico por 100 gramas de néctar.

Determinou-se a atividade antioxidante pela capacidade dos antioxidantes presentes na amostra em sequestrar o radical estável 2,2-difenil-1-picrilhidrazila (DPPH), segundo o método citado por MILIAUSKAS, VENSKUTONIS e VAN BEEK (2004). Os resultados foram expressos em percentual de sequestro de radicais livres (\%SRL), calculado em relação ao decréscimo da absorbância das amostras, correlacionado ao decréscimo da absorbância do controle (solução de DPPH), conforme a equação 1:

$$
\% \text { inibição }(\% \mathrm{SRL})=[(\mathrm{Ab}-\mathrm{Aa}) / \mathrm{Ab}] \times 100
$$

Em que:

$\mathrm{Aa}=$ absorção da amostra aos 40 minutos de incubação;

$A b=$ absorção da solução de DPPH em zero minuto de incubação (branco).

A avaliação das características físico-químicas do néctar de amora-preta decorreu paralelamente às avaliações do seu potencial antioxidante. Foram determinados, em triplicata, sólidos solúveis totais ('Brix) por leitura direta em refratômetro de bancada, $\mathrm{pH}$ por leitura direta em potenciômetro (Digimed - DM20) e acidez total titulável (\% ácido cítrico) de acordo com o IAL (1985). Determinou-se a viscosidade aparente em Haake Viscosimeter, nas condições de $20^{\circ} \mathrm{C}, 100 \mathrm{rpm}$, tempo de 30 segundos e spindle L1, conforme MACHADO (2007).

Os resultados das avaliações físico-químicas e do potencial antioxidante do néctar de amorapreta foram analisados estatisticamente pelo software STATISTICA versão 6.0 (STATSOFT, 2001), sendo a significância estatística estudada mediante análise de variância (ANOVA), teste $F$ e teste de Tukey com nível de significância de 5\% para comparação das médias.

\section{RESULTADOS E DISCUSSÃO}

Os resultados das avaliações físico-químicas, realizadas em néctar de amora-preta congelado e armazenado durante 90 dias, encontram-se descritos na Tabela 1. 


\section{TABELA - 1 CARACTERÍSTICAS FÍSICO-QUÍMICAS DE NÉCTAR DE AMORA-PRETA CONGELADO DURANTE ARMAZENAMENTO}

\begin{tabular}{ccccc}
\hline $\begin{array}{c}\text { Armazenamento } \\
\text { (dias) }\end{array}$ & $\begin{array}{c}\text { Sólidos } \\
\text { solúveis totais } \\
\left({ }^{\circ} \text { Brix) }\right.\end{array}$ & $\mathrm{pH}$ & $\begin{array}{c}\text { Acidez total }(\% \\
\text { ácido cítrico) }\end{array}$ & $\begin{array}{c}\text { Viscosidade aparente } \\
\text { (mPas) }\end{array}$ \\
\hline 0 & $13,0 \pm 0,00^{\mathrm{a}}$ & $2,41 \pm 0,006^{\mathrm{c}}$ & $0,54 \pm 0,00^{\mathrm{b}}$ & $34,76 \pm 0,75 \mathrm{~d}$ \\
15 & $14,5 \pm 0,00^{\mathrm{a}}$ & $2,50 \pm 0,00^{\mathrm{a}}$ & $0,51 \pm 0,02^{\mathrm{bc}}$ & $35,03 \pm 0,06 \mathrm{~d}^{\mathrm{d}}$ \\
30 & $14,0 \pm 0,00^{\mathrm{a}}$ & $2,37 \pm 0,006^{\mathrm{d}}$ & $0,60 \pm 0,03^{\mathrm{a}}$ & $35,00 \pm 0,00^{\mathrm{d}}$ \\
45 & $14,5 \pm 0,00^{\mathrm{a}}$ & $2,27 \pm 0,01^{\mathrm{g}}$ & $0,53 \pm 0,02^{\mathrm{b}}$ & $29,63 \pm 0,72^{\mathrm{e}}$ \\
& & & & \\
60 & $14,0 \pm 0,00^{\mathrm{a}}$ & $2,46 \pm 0,01^{\mathrm{b}}$ & $0,52 \pm 0,02 \mathrm{bc}$ & $41,40 \pm 0,10^{\mathrm{b}}$ \\
75 & $14,0 \pm 0,00^{\mathrm{a}}$ & $2,33 \pm 0,00^{\mathrm{f}}$ & $0,47 \pm 0,00^{\mathrm{c}}$ & $45,05 \pm 0,05^{\mathrm{a}}$ \\
90 & $14,0 \pm 0,00^{\mathrm{a}}$ & $2,35 \pm 0,00{ }^{\mathrm{e}}$ & $0,52 \pm 0,01^{\mathrm{b}}$ & $36,46 \pm 0,35^{\mathrm{c}}$ \\
\hline
\end{tabular}

Os valores representam as médias de 3 repetições \pm desvio padrão.

Letras distintas na mesma coluna indicam diferença significativa pela Análise de Variância (ANOVA), ou pelo teste de Tukey, ao nível de $5 \%$ de probabilidade.

O teor de sólidos solúveis totais (SST) não variou estatisticamente, mantendo-se praticamente constante durante todo o período em que o produto ficou armazenado (90 dias). MOTA (2006) observou resultado contrário ao avaliar suco de amora-preta, verificando diferença significativa $(\mathrm{pd}<0,05)$ no teor de SST do produto tanto em temperatura ambiente como sob refrigeração. Entretanto, LAVINAS et al. (2006), ao trabalharem com suco de caju, não evidenciaram variação no teor de SST do produto quando armazenado sob congelamento $\left(-22 \pm 1^{\circ} \mathrm{C}\right)$.

$\mathrm{O}$ pH diferiu estatisticamente $(\mathrm{pd}<0,05)$ em todos os períodos de análise, apresentando alternada diminuição e elevação. O mesmo comportamento não foi constatado por LEITÃO (2007) em néctar de amora-preta, que verificou aumento progressivo do $\mathrm{pH}$ em ambas as temperaturas de armazenamento do produto (ambiente e refrigeração), durante todo o experimento (90 dias).

A acidez diferiu estatisticamente ( $p d<0,05)$ aos 30 e 75 dias de armazenamento, quando foram observados os maiores e os menores valores, respectivamente. Em trabalho realizado com suco de limão Tahiti (PEDRÃO et al., 1999), os autores não encontraram diferença de acidez entre as amostras armazenadas sob congelamento a $-18^{\circ} \mathrm{C}$. Segundo eles, o congelamento pode ser adequado para armazenar sucos e polpas de frutas por reduzir o risco de crescimento de microrganismos. De acordo com BARRUFALDI e OLIVEIRA (1998), o processo de decomposição do alimento geralmente altera sua concentração de íons hidrogênio e, por consequência, sua acidez. Assim, a relação temperatura versus decomposição é limitante no aumento da acidez em produtos de frutas. LEITÃO (2007) observou essa relação mediante aumento de acidez (8,6\%) em néctar de amora-preta, armazenado em temperatura ambiente $\left(16 \pm 3^{\circ} \mathrm{C}\right)$ e diminuição da acidez para o mesmo produto submetido à refrigeração $\left(4 \pm 2^{\circ} \mathrm{C}\right)$.

Variações significativas de viscosidade aparente $(p d<0,05)$ foram evidenciadas a partir de 45 dias de armazenamento do produto. As elevadas viscosidades encontradas provêm do fato de o produto não ter sofrido nenhum processo de filtração e as diferenças apresentadas podem estar relacionadas ao momento do envase. O grau de homogeneização do produto pode não ter sido o mesmo, fazendo com que algumas amostras apresentassem maior ou menor teor de polpa em suspensão. Para suco de maracujá in natura e submetido à microfiltração, SILVA et al. (2005) encontraram viscosidade aparente de 6,20 e 1,21 mPas, respectivamente. Esses resultados mostram a influência das operações de filtração nas taxas de viscosidade de bebidas como suco e néctares, sendo operações que promovem remoção quase que completa da polpa em suspensão, resultando em produto clarificado, límpido e pouco viscoso.

Os resultados das avaliações que determinam o potencial antioxidante do néctar de amorapreta submetido ao congelamento e armazenado durante 90 dias encontram-se descritos na Tabela 2. 


\section{TABELA 2 - POTENCIAL ANTIOXIDANTE DE NÉCTAR DE AMORA-PRETA CONGELADO DURANTE O ARMAZENAMENTO}

\begin{tabular}{|c|c|c|c|c|}
\hline $\begin{array}{c}\text { Armaze- } \\
\text { namento } \\
\text { (dias) }\end{array}$ & $\begin{array}{l}\text { Compostos } \\
\text { fenólicos totais (mg } \\
\text { GAE. } 100 \mathrm{~g}^{-1} \text { néctar) }\end{array}$ & $\begin{array}{c}\text { Antocianinas totais } \\
\text { (mg GYD-3-G.100 } \\
\mathrm{g}^{-1} \text { néctar) }\end{array}$ & $\begin{array}{c}\text { Ácido ascórbico (mg } \\
\text { ácido ascórbico. } 100 \mathrm{~g} \\
{ }_{1} \text { néctar) }\end{array}$ & $\begin{array}{l}\text { Atividade antioxidante } \\
\text { (\% Inibição DPPH) }\end{array}$ \\
\hline 0 & $191,19 \pm 0,00^{a}$ & $118,95 \pm 0,06^{a}$ & $10,78 \pm 0,26^{a}$ & $75,89 \pm 0,02^{a}$ \\
\hline 15 & $170,00 \pm 0,00 \mathrm{~d}$ & $116,49 \pm 0,05^{\mathrm{c}}$ & $10,26 \pm 0,06^{b}$ & $72,36 \pm 0,05^{b}$ \\
\hline 30 & $153,84 \pm 0,00$ e & $117,54 \pm 0,24$ b & $9,69 \pm 0,02^{\mathrm{c}}$ & $70,046 \pm 0,06$ \\
\hline 45 & $168,50 \pm 1,54 \mathrm{~d}$ & $115,33 \pm 0,13 d$ & $9,01 \pm 0,07 d$ & $70,46 \pm 0,05 d$ \\
\hline 60 & $183,59 \pm 2,31^{b}$ & $118,16 \pm 0,22^{b}$ & $9,95 \pm 0,06$ bc & $72,13 \pm 0,05^{c}$ \\
\hline 75 & $168,04+1,08{ }^{d}$ & $110,84 \pm 0,14$ & $6,67 \pm 0,12$ & $69,35 \pm 0,13$ \\
\hline 90 & $173,45 \pm 0,00$ & $115,48 \pm 0,54$ & $7,66 \pm 0,06$ e & $70,12 \pm 0,05$ \\
\hline
\end{tabular}

Os valores representam as médias de 3 repetições \pm desvio padrão.

Letras distintas na mesma coluna indicam diferença significativa pela Análise de Variância (ANOVA), ou pelo teste de Tukey, ao nível de 5\% de probabilidade.

GYD-3-G = cianidina-3-glicosídio; GAE = ácido gálico equivalente.

Os teores de compostos fenólicos totais decresceram nos primeiros 30 dias de armazenamento do produto, apresentando posterior elevação a partir do quadragésimo quinto dia. LEITÃO (2007) verificou acréscimo no teor de fenóis totais de aproximadamente 18,86\% em néctar de amora-preta armazenado sob refrigeração. ANTUNES, GONÇALVES e TREVISAN (2006) observaram incremento de fenóis totais em frutos de amora-preta armazenados sob refrigeração $\left(2^{\circ} \mathrm{C}\right)$ até o nono dia de armazenamento, seguido de ligeira degradação até o final do experimento. Segundo SELLAPPAN, AKOH e KREWER (2002), esse comportamento pode ser decorrente de reações de copigmentação ocorridas durante o armazenamento. De acordo com MENEZES (1994), a redução desses compostos pode ser devida a processos de complexação e polimerização de taninos.

As diferenças entre os teores de antocianinas não foram muito amplas, sendo significativas $(\mathrm{pd}<0,05)$ aos 15 e 75 dias de armazenamento, indicando que o congelamento constitui opção para a manutenção desse tipo de composto. MAEDA et al. (2007) observaram redução progressiva de antocianinas em néctar de camu-camu armazenado, tanto sob refrigeração como a temperatura ambiente. No estudo de MOTA (2006), o tempo de armazenamento também contribuiu para a redução dessa substância. Entretanto, LEITÃO (2007) praticamente não detectou degradação de antocianinas em néctar de amora-preta armazenado sob refrigeração $\left(4 \pm 2^{\circ} \mathrm{C}\right)$ durante 90 dias. Observou também tendência de aumento desses pigmentos até o sexagésimo dia de armazenamento. De acordo com BARRUFALDI e OLIVEIRA (1998), o congelamento de alimentos é capaz de retardar praticamente todo o processo metabólico dos mesmos, sendo que quanto mais baixa for a temperatura de armazenamento, mais lentas serão as possíveis alterações. Esse comportamento pode explicar os baixos índices de degradação dos compostos antociânicos do néctar de amora-preta congelado durante o armazenamento.

O ácido ascórbico variou significativamente $(\mathrm{pd}<0,05)$ aos $30,45,75$ e 90 dias. As maiores perdas dessa substância ocorreram no mesmo período (75 dias de armazenamento) em que foram evidenciadas as maiores perdas de antocianinas. De acordo com BOBBIO e BOBBIO (1992), as antocianinas interagem com o ácido ascórbico produzindo polímeros de produtos de degradação que diminuem sua estabilidade. YAMASHITA et al. (2003) observaram perdas de até $43 \%$ de vitamina $\mathrm{C}$ em produtos de acerola armazenados a $-12^{\circ} \mathrm{C}$ e de $19 \%$ nos armazenados a $-18^{\circ} \mathrm{C}$ durante 120 dias de estocagem. LEITÃO (2007) verificou que a degradação dessa vitamina em néctar de amora-preta foi de $82,32 \%$ no produto armazenado sob refrigeração e de $100 \%$ em temperatura ambiente. Isso evidencia que quanto menor a temperatura de armazenamento dos sucos, menor será a intensidade de degradação dos seus compostos funcionais. 


\section{TABELA 2 - POTENCIAL ANTIOXIDANTE DE NÉCTAR DE AMORA-PRETA CONGELADO DURANTE O ARMAZENAMENTO}

\begin{tabular}{|c|c|c|c|c|}
\hline $\begin{array}{c}\text { Armaze- } \\
\text { namento } \\
\text { (dias) }\end{array}$ & $\begin{array}{l}\text { Compostos } \\
\text { fenólicos totais (mg } \\
\text { GAE. } 100 \mathrm{~g}^{-1} \text { néctar) }\end{array}$ & $\begin{array}{c}\text { Antocianinas totais } \\
\text { (mg GYD-3-G.100 } \\
\mathrm{g}^{-1} \text { néctar) }\end{array}$ & $\begin{array}{c}\text { Ácido ascórbico (mg } \\
\text { ácido ascórbico. } 100 \mathrm{~g} \\
{ }_{1} \text { néctar) }\end{array}$ & $\begin{array}{l}\text { Atividade antioxidante } \\
\text { (\% Inibição DPPH) }\end{array}$ \\
\hline 0 & $191,19 \pm 0,00^{a}$ & $118,95 \pm 0,06^{a}$ & $10,78 \pm 0,26^{a}$ & $75,89 \pm 0,02^{a}$ \\
\hline 15 & $170,00 \pm 0,00 \mathrm{~d}$ & $116,49 \pm 0,05^{\mathrm{c}}$ & $10,26 \pm 0,06^{b}$ & $72,36 \pm 0,05^{b}$ \\
\hline 30 & $153,84 \pm 0,00$ e & $117,54 \pm 0,24$ b & $9,69 \pm 0,02^{\mathrm{c}}$ & $70,046 \pm 0,06$ \\
\hline 45 & $168,50 \pm 1,54 \mathrm{~d}$ & $115,33 \pm 0,13 d$ & $9,01 \pm 0,07 d$ & $70,46 \pm 0,05 d$ \\
\hline 60 & $183,59 \pm 2,31^{b}$ & $118,16 \pm 0,22^{b}$ & $9,95 \pm 0,06$ bc & $72,13 \pm 0,05^{c}$ \\
\hline 75 & $168,04+1,08{ }^{d}$ & $110,84 \pm 0,14$ & $6,67 \pm 0,12$ & $69,35 \pm 0,13$ \\
\hline 90 & $173,45 \pm 0,00$ & $115,48 \pm 0,54$ & $7,66 \pm 0,06$ e & $70,12 \pm 0,05$ \\
\hline
\end{tabular}

Os valores representam as médias de 3 repetições \pm desvio padrão.

Letras distintas na mesma coluna indicam diferença significativa pela Análise de Variância (ANOVA), ou pelo teste de Tukey, ao nível de 5\% de probabilidade.

GYD-3-G = cianidina-3-glicosídio; GAE = ácido gálico equivalente.

Os teores de compostos fenólicos totais decresceram nos primeiros 30 dias de armazenamento do produto, apresentando posterior elevação a partir do quadragésimo quinto dia. LEITÃO (2007) verificou acréscimo no teor de fenóis totais de aproximadamente 18,86\% em néctar de amora-preta armazenado sob refrigeração. ANTUNES, GONÇALVES e TREVISAN (2006) observaram incremento de fenóis totais em frutos de amora-preta armazenados sob refrigeração $\left(2^{\circ} \mathrm{C}\right)$ até o nono dia de armazenamento, seguido de ligeira degradação até o final do experimento. Segundo SELLAPPAN, AKOH e KREWER (2002), esse comportamento pode ser decorrente de reações de copigmentação ocorridas durante o armazenamento. De acordo com MENEZES (1994), a redução desses compostos pode ser devida a processos de complexação e polimerização de taninos.

As diferenças entre os teores de antocianinas não foram muito amplas, sendo significativas $(\mathrm{pd}<0,05)$ aos 15 e 75 dias de armazenamento, indicando que o congelamento constitui opção para a manutenção desse tipo de composto. MAEDA et al. (2007) observaram redução progressiva de antocianinas em néctar de camu-camu armazenado, tanto sob refrigeração como a temperatura ambiente. No estudo de MOTA (2006), o tempo de armazenamento também contribuiu para a redução dessa substância. Entretanto, LEITÃO (2007) praticamente não detectou degradação de antocianinas em néctar de amora-preta armazenado sob refrigeração $\left(4 \pm 2^{\circ} \mathrm{C}\right)$ durante 90 dias. Observou também tendência de aumento desses pigmentos até o sexagésimo dia de armazenamento. De acordo com BARRUFALDI e OLIVEIRA (1998), o congelamento de alimentos é capaz de retardar praticamente todo o processo metabólico dos mesmos, sendo que quanto mais baixa for a temperatura de armazenamento, mais lentas serão as possíveis alterações. Esse comportamento pode explicar os baixos índices de degradação dos compostos antociânicos do néctar de amora-preta congelado durante o armazenamento.

O ácido ascórbico variou significativamente $(\mathrm{pd}<0,05)$ aos $30,45,75$ e 90 dias. As maiores perdas dessa substância ocorreram no mesmo período (75 dias de armazenamento) em que foram evidenciadas as maiores perdas de antocianinas. De acordo com BOBBIO e BOBBIO (1992), as antocianinas interagem com o ácido ascórbico produzindo polímeros de produtos de degradação que diminuem sua estabilidade. YAMASHITA et al. (2003) observaram perdas de até $43 \%$ de vitamina $\mathrm{C}$ em produtos de acerola armazenados a $-12^{\circ} \mathrm{C}$ e de $19 \%$ nos armazenados a $-18^{\circ} \mathrm{C}$ durante 120 dias de estocagem. LEITÃO (2007) verificou que a degradação dessa vitamina em néctar de amora-preta foi de $82,32 \%$ no produto armazenado sob refrigeração e de $100 \%$ em temperatura ambiente. Isso evidencia que quanto menor a temperatura de armazenamento dos sucos, menor será a intensidade de degradação dos seus compostos funcionais. 
A atividade antioxidante do produto diferiu estatisticamente $(\mathrm{pd}<0,05)$ em praticamente todos os intervalos de tempo estudados, exceto aos 30 e 90 dias. O potencial antioxidante decresceu até 45 dias de armazenamento, aumentou aos 60 dias e voltou a diminuir após esse período até o final do experimento. LEITÃO (2007) verificou tendência ao crescimento do potencial antioxidante em néctar de amora-preta de, aproximadamente, $9 \%$ em ambas as condições em que o produto foi estudado (temperatura ambiente e de refrigeração). Neste trabalho, a diminuição da atividade antioxidante está diretamente associada aos decréscimos de compostos fenólicos e antocianinas, indicando que essas substâncias são as possíveis responsáveis pelo potencial antioxidante do néctar de amora-preta estudado.

Na Tabela 3 estão descritos os resultados das análises de correlação de Pearson realizadas entre as variáveis compostos fenólicos totais, antocianinas totais, ácido ascórbico e atividade antioxidante de néctar de amora-preta.

\section{TABELA 3 - COEFICIENTES DE CORRELAÇÃO DE PEARSON PARA AS VARIÁVEIS COMPOSTOS FENÓLICOS TOTAIS, ANTOCIANINAS TOTAIS, ÁCIDO ASCÓRBICO E ATIVIDADE ANTIOXIDANTE DE NÉCTAR CONGELADO DE AMORA-PRETA SUBMETIDO A ARMAZENAMENTO}

\begin{tabular}{ccccc}
\hline Variáveis & $\begin{array}{c}\text { Compostos } \\
\text { fenólicos } \\
\text { totais }\end{array}$ & $\begin{array}{c}\text { Antocianinas } \\
\text { totais }\end{array}$ & $\begin{array}{c}\text { Ácido } \\
\text { ascórbico }\end{array}$ & $\begin{array}{c}\text { Atividade } \\
\text { antioxidante }\end{array}$ \\
\hline $\begin{array}{c}\text { Compostos fenólicos } \\
\text { totais }\end{array}$ & - & $0,38^{\text {ns }}$ & $0,34^{\text {ns }}$ & $0,78^{*}$ \\
$\begin{array}{c}\text { Antocianinas totais } \\
\text { Ácido ascórbico } \\
\begin{array}{c}\text { Atividade } \\
\text { antioxidante }\end{array}\end{array}$ & 0,78 & 0,69 & $0,90^{*}$ & $0,69^{*}$ \\
\hline
\end{tabular}

Nível de significância a 5\% de probabilidade, pelo teste t.

ns = não significativo.

$(-)$ = não existe correlação.

Os resultados mostraram haver correlação significativa $(p d<0,05)$ entre as variáveis compostos fenólicos totais, antocianinas totais e ácido ascórbico com a atividade antioxidante em néctar de amora-preta, evidenciando tendência de elevação da atividade antioxidante do produto conforme 0 aumento do teor dessas substâncias. Além disso, verificou-se forte correlação entre as variáveis antocianinas totais e o ácido ascórbico, indicando que à medida que os compostos antociânicos se degradam os teores de ácido ascórbico também tendem a diminuir.

SANTOS et al. (2008) evidenciaram correlação positiva entre as variáveis compostos fenólicos e antocianinas totais com a atividade antioxidante de polpas de açaí, atribuindo os elevados valores de atividade antioxidante das polpas a esses compostos. KALT et al. (1999) igualmente encontraram correlação positiva entre a capacidade antioxidante total e os teores de antocianinas totais e compostos fenólicos totais de pequenas frutas como morango, framboesa e mirtilo.

\section{CONCLUSÃO}

O congelamento por 90 dias, como método de conservação, permite manter a estabilidade físico-química e o potencial antioxidante de néctar de amora-preta, evitando que compostos potencialmente funcionais (compostos fenólicos totais, antocianinas e ácido ascórbico) inerentes à fruta fossem altamente degradados. 


\section{ABSTRACT \\ FREEZING INFLUENCE ON THE PHYSICO-CHEMICAL CHARACTERISTICS AND ANTIOXIDANT POTENTIAL OFBLACKBERRY NECTAR}

The presence of bioactive compounds in blackberry confers functional properties that stimulate the development of derived products. However, factors such as the processing and the storage are essential for the stability of these products and to maintain functionality. The objective of this work was to evaluate the influence of freezing on the physico-chemical characteristics and the antioxidant potential of blackberry nectar during 90 days of storage. The product was evaluated every 15 days for total phenolic compounds, anthocyanin, vitamin $\mathrm{C}$, antioxidant capacity, total solubles solids, $\mathrm{pH}$, total acidity and apparent viscosity. At the end of the study it was verified that freezing, as a conservation method, maintain the physico-chemical stability and antioxidant potential of blackberry nectar.

KEY-WORDS: BLACKBERRY; NECTAR; ANTIOXIDANT CAPACITY.

\section{REFERÊNCIAS}

11 ANTUNES, L. E. C.; CHALFUN, N. N. J.; REGINA, M. de A.; DUARTE FILHO, J. Blossom and ripening periods of blackberry varieties in Brazil. Journal American Pomological Society, v. 54, n. 4, p. 164-168, 2000.

2 ANTUNES, L.E.C. Amora-preta: nova opção de cultivo no Brasil. Ciência Rural, v. 32, n. 1, p. 151-158, 2002.

3 ANTUNES, L. E. C.; GONÇALVES, E. D.; TREVISAN, R. Alterações de compostos fenólicos e pectina em pós-colheita de frutos de amora-preta. Revista Brasileira de Agrociência, v. 12, n. 1, p. 57-61, 2006.

4 BARBOZA, G. L. G. Obtenção e caracterização de sucos clarificados de amora-preta (Rubus spp. L.). Pelotas, 1999. 63 p. Dissertação (Mestrado em Ciência e Tecnologia Agroindustrial), Faculdade de Agronomia Eliseu Maciel, Universidade Federal Pelotas (UFPel).

5 BARRUfaldI, R.; OLIVEIRA, M. N. de. Fundamentos de tecnologia de alimentos. São Paulo: Atheneu Editora, 1998. v.3.

6 BOBBIO, G. O.; BOBBIO, P.A. Química do processamento de alimentos. 2. ed. São Paulo: Editora Varela, 1992.

7 CERQUeIRA, F. M.; MEDEIROS, M. H. G. de; AUGUSTO, O. Antioxidantes dietéticos: controvérsias e perspectivas. Química Nova, v. 30, n. 2, p. 441-449, 2007.

8 CHITARRA, M. I. F. Processamento mínimo de frutas e hortaliças. Lavras: UFLA/FAEPE, 2000.

9 CONTRERAS, G. E.; STRONG III, F.C.; GUERNELLI, O. Determinação de ácido ascórbico (Vitamina C) por redução de íons cúpricos. Química Nova, v. 7, n. 2, p. 60-64, 1984.

10 ELISIA, I.; HU, C.; POPOVICH, D.G.; KITTS, D.D. Antioxidant assessment of an anthocyanin-enriched blackberry extract. Food Chemistry, v. 101, n. 3, p. 1052-1058, 2007.

11 FULEKI, T.; FRANCIS, F. J. Quantitative methods for anthocyanins 1. Extraction and determination of total anthocyanin in cranberries. Journal of Food Science, v. 33, p. 72-77, 1968.

12 GARCÍA-ALONSO, M.; PASCUAL-TERESA, S.; SANTOS-BUELGA, C.; RIVAS-GONZALO, J. C. Evaluation of the antioxidant properties of fruits. Food Chemistry, v. 84, p. 13-18, 2004.

13 GIBNEY, M. J.; MACDONALD, I. A.; ROCHE, H. M. Nutrição e metabolismo. Rio de Janeiro: Guanabara Koogan, 2006.

14 GRANADA, G. L.; VENDRUSCOLO, J. L.; TREPTOW, R. O. Caracterização química e sensorial de sucos clarificados de amora-preta (Rubus spp. L.). Revista Brasileira de Agrociência, v. 7, n. 2, p. 143-147, 2001.

15 HASSIMOTTO, N. M. A.; GENOVESE, M. I.; LAJOLO, F. M. Identificação e caracterização de antocianinas de amora (Morus, sp.) por espectrofotometria UV-Visivel. In: CONGRESSO BRASILEIRO DE CIÊNCIA E TECNOLOGIA DE ALIMENTOS, 19., Recife, 2004. Recife. Anais... Recife: SBCTA, 2004. 1 CD-ROM

16 HASSIMOTTO, N. M. A.; GOMEZ, M. L. P. A.; MOTA, R. V. da; CORDENUNSI, B. R.; LAJOLO, F. M. Compostos antioxidantes da amora-preta (Rubus sp.). In: CONGRESSO BRASILEIRO DE CIÊNCIAE TECNOLOGIA DEALIMENTOS, 19., Recife, 2004. Recife. Anais... Recife: SBCTA, 2004. 1 CD-ROM

17 IAL. Instituto Adolfo Lutz. Normas analíticas do Instituto Adolfo Lutz: métodos químicos e físicos para análise de alimentos. 3. ed. São Paulo, 1985. v.1. 
18 JACKMAN, R. L.; SMITH, J. L. Anthocyanins and betalains. In: HENDRY, G.A.F.; HOUGHTON, J.D. Natural food colorants. New York-USA: AVI, 1992.

19 KIRALP, S.; TOPPARE, L. Polyphenol content in selected Turkish wines, an alternative method of detection of phenolics. Process Biochemistry, v. 41, p. 236-239, 2006.

20 KALT, W.; FORNEY, C. F.; MARTIN, A.; PRIOR, R. L. Antioxidant capacity, vitamin C, phenolics and anthocyanins after fresh storage of small fruits. Journal of Agricultural and Food Chemistry, v. 47, n. 11, p. 4638-4644, 1999.

21 LAVINAS, F. C; ALMEIDA, N. C. de; MIGUEL, M. A. L.; LOPES, M. L. M.; VALENTE-MESQUITA, V. L. Estudo da estabilidade química e microbiológica do suco de caju in natura armazenado em diferentes condições de estocagem. Ciência e Tecnologia de Alimentos, v. 26, n. 4, p. 875-883, 2006.

22 LEITÃO, A. M. Estabilidade físico-química, microbiológica e sensorial de néctar de amora-preta (Rubus spp.), Cv. Tupy, embalado em polipropileno, no armazenamento. Pelotas, 2007, 64 p. Dissertação (Mestrado em Ciência e Tecnologia Agroindustrial), Faculdade de Agronomia Eliseu Maciel, Universidade Federal de Pelotas (UFPel).

23 MÄÄTÄ-RIIHINEN, K. R.; KAMAL-ELDIN, A.; TÖRRÖNEN, A. R. Identification and quantification of phenolic compounds in berries of Fragaria and Rubus species (family Rosaceae). Journal of Agricultural and Food Chemistry, v. 52, p. 6178-6187, 2004.

24 MACHADO, M. R. G. Bebida de soja fermentada com Lactobacillus acidophilus: viabilidade celular, avaliação sensorial, armazenamento e resposta funcional. Pelotas, 2007, 101 p. Tese (Doutorado em Ciência e Tecnologia Agroindustrial), Faculdade de Agronomia Eliseu Maciel, Universidade Federal de Pelotas (UFPel).

25 MAEDA, R. N.; PANTOJA, L.; YUYAMA, L. K. O.; CHAAR, J. M. Estabilidade de ácido ascórbico e antocianinas em néctar de camu-camu (Myrciaria dubia (H. B. K.) McVaugh). Ciência e Tecnologia de Alimentos, v. 27, n. 2, p. 313-316, 2007.

26 MENEZES, J. B. Pós-colheita do pedúnculo do caju. Informe Agropecuário, v. 17, n. 180, p. 13-17, 1994.

27 MILIAUSKAS, G.; VENSKUTONIS, P. R.; VAN BEEK, T. A. Screening of radical scavenging activity of some medicinal and aromatic plant extracts. Food Chemistry, v. 875, p. 231-237, 2004.

28 MOTA, R. V. Caracterização do suco de amora-preta elaborado em extrator caseiro. Ciência e Tecnologia de Alimentos, v. 26, n. 2, p. 303-308, 2006.

29 PEDRÃO, M.R.; BELEIA, A.; MODESTA, R.C.D.; PRUDENCIO-FERREIRA, S. H. Estabilidade físico-química e sensorial do suco de limão Tahiti natural e adoçado, congelado. Ciência e Tecnologia de Alimentos, v. 19, n. 2, p. 282-286, 1999.

30 SANTOS, G. M. dos; MAIA, G. A.; SOUSA, P. H. M. de; COSTA, J. M. C. da; FIGUEIREDO, R. W. de; PRADO, G. M. do. Correlação entre atividade antioxidante e compostos bioativos de polpas comerciais de açaí (Euterpe oleracea Mart). Archivos Latinoamericanos de Nutrición, v. 58, n. 2, p. 187-192, 2008.

31 SELLAPPAN, S.; AKOH, C. C.; KREWER, G. Phenolic compounds and antioxidant capacity of Georgia-Grown Blueberries and Blackberries. Journal of Agricultural and Food Chemistry, v. 50, p. 2432-2438, 2002.

32 SILVA, T. T.; MODESTA, R. C. D.; PENHA, E. das M.; MATTA, V. M.; CABRAL, L. M. C. Suco de maracujá orgânico processado por microfiltração. Pesquisa Agropecuária Brasileira, v. 40, n. 4, p. 419-422, 2005.

33 STATSOFT INC. Statistica. Versão 6.0. Tulsa/EUA, 2001. 1 CD-ROM

34 TÜREMIS, N.; KAFKAS, E.; KAFKAS, S.; KURKCUOGLU, M.; BASER, K.H.C. Determination of aroma compounds in blackberry by GC/MS analysis. Chemistry of Natural Compounds, v. 39, n. 2, p. 174-176, 2003.

35 YAMASHITA, F.; BENASSI, M. T.; TONZAR, A. C.; MORIYA, S.; FERNANDES, J. G. Produtos de acerola: estudos da estabilidade de vitamina C. Ciência e Tecnologia Alimentos, v. 23, n. 1, p. 92-94, 2003. 